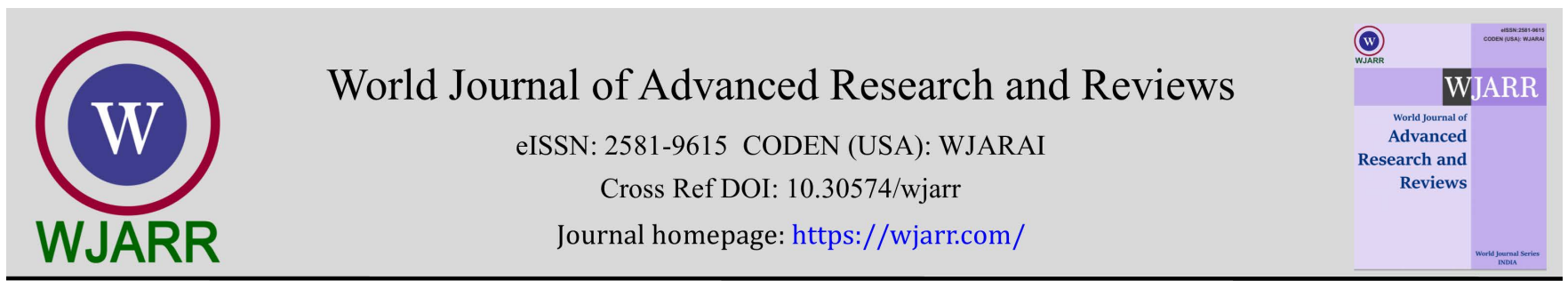

(REVIEW ARTICLE)

\title{
An exploration into the conceptual, factual and biblical significance of names
}

\author{
Felix. Chukwuma Aguboshim* \\ Department of Computer Science, Federal Polytechnic, Oko, Nigeria.
}

World Journal of Advanced Research and Reviews, 2021, 11(03), 127-133

Publication history: Received on 08 August 2021; revised on 12 September 2021; accepted on 14 September 2021

Article DOI: https://doi.org/10.30574/wjarr.2021.11.3.0439

\begin{abstract}
Globally, works of literature have significantly revealed that everything that existed has a name. The name has significant importance in realizing the sustainable identity, purpose, performance, or destiny of what is named. Despite these laudable significances, numerous investigations have shown that the impact of these naming supposition, ideas, and explanations among the conceptual, factual, and biblical or covenant naming concepts are obscure. The King James Bible was adopted as the conceptual framework for this study because all things (including the significance of naming) are made and upheld by the word of God. The researcher explored a narrative review, analysis, and synthesis of vast works of literature that revealed significant information and insights on the symbolism, purpose, characteristics, importance, and significance of names, especially in Igbo, Nigeria, Africa. The researcher also extracted some documentaries from King James Bible, and peer-reviewed articles within the last five years from electronic databases, engaging some keywords like "Significance of naming in Africa", "Covenant naming", "purpose of naming", etc. Results show that names are not mere tags for simple identification, but that names connect the name bearers to their hopes, calling, and destiny in life. Results also show that names have cultural and historical connections that can impact the significant personality of the person named, his sense of belonging in a community, and his hope for his glorious destiny, and place in the world at large. Results and insights from this study may have a positive social impact on naming, research and innovations on the significance of names.
\end{abstract}

Keywords: Bible; Covenant naming; Naming; Purpose of Name; Name

\section{Introduction}

"Everything is in a name" is the Igbo-Nigeria answer to the Shakespearean question "What's in a name?" There is a force of power in spoken words that impacts the name bearer when a child's name is pronounced especially at child covenant naming ceremonies. A covenant is a conditional promise made to humanity by God usually ratified with an oath. A covenant name is a prophetic name; a name with a conditional promise, prophetic by itself, made to humanity by God as revealed, and given to an individual, with the hope and faith that the name bearer will live to the expectations of the hopes, calling, mission, and destiny embedded and propagated in the giving name. Choosing a good name is better than great riches (King James Version, 2017, Proverbs 22:1). This is because names have a covenant impact on the name bearer. However, the significance of names outside the biblical concept, the conceptual framework of this study, has continued to be controversial globally.

In the traditional Igbo Nigeria or African culture, naming or re-naming exits. Naming can come as an initial naming of a newborn, as family, peer group nicknames, or as an auxiliary, especially in another language. Re-naming may also occur to give the bearer a new hope in destiny, as in the case of Jacob whose name was changed to Israel (Genesis 32:26-28). A child who is fussy or sick or bothered by a spirit, or a woman that takes after the name of her husband after marriage may have a name change. A person can assume a re-naming following his new status or the task ahead of him, as in the

\footnotetext{
${ }^{*}$ Corresponding author: Felix. Chukwuma. Aguboshim

Department of Computer Science, Federal Polytechnic, Oko, Nigeria.

Copyright (C) 2021 Author(s) retain the copyright of this article. This article is published under the terms of the Creative Commons Attribution Liscense 4.0.
} 
case of Abraham whose name was changed from Abram to Abraham to suit his new status (Genesis 17:4-6). It is observed that the social semantic content of names is also significant as it plays an important role in protecting the destinies of individuals and their choices of their spouses. Some others have the idea that human names are seen as a subset of proper names, though classified together as nominal, that refer to specific objects, places, persons, or classes, and no other [1]. In this wise, [1] claimed that both proper names and personal names that identify individual persons, whether divine or human, are grouped together as common nouns that make sense but not reference.

The idea that a human name is a mere common noun that makes sense but does not reference any particular human, and so does not have reference to the individual's hopes, calling, and destiny in life is not always correct. Each of the person named Adam, Eve, Abraham, etc. does have references to the individual's origin, hopes, calling, or destiny in life. Aside from physical referencing, human names in Igbo, Jewish or biblical culture as believed and practiced by some African traditions are divine (from God), they make sense, and have reference to the individual's hopes, calling, and destiny in life. The meaning attached to names of individuals may have denotative (meaning by dictionary), connotative (meaning by suggesting of mind), social (social context), affective or emotive (convey about personal feeling), reflected (multiple conceptual meaning), collocative (association of words), thematic (message of the meaning), covenant, or have a semantic function beyond the above meanings. These meanings attached to names of individuals have continued to be arguable and remain the focus of ongoing discussions. In the Igbo -Nigerian culture or global African culture, a surname roots the individual to his family history and family tradition, while first names establish their particular identity and personality.

It is believed that names tell a story of who we are, what we shall be and become, or have a way of impacting one as one grows up. Some other cultures believe that names, like all words, have definitions. In the Middle East culture, the meaning of the name of a child is often looked upon as a prediction or prophecy for what kind of person that child would grow up to be. People from other perspectives have argued that it does not matter what one's name is, claiming that one does not become what one is called, neither is one called what one is [2] and [3]. They see names as simply a tag for simple identification. Some researchers claimed that personal names may influence the name bearer's conduct and emotional attitude [4], culture and perceptions of cultural identity [5], hopes and destiny [6], and the name bearer's healthy and psychological self-image [7]. To others, especially in West Africa, and Igbo Nigeria in particular, a name is much more than a simple, functional tag to identify someone [4] and [6]. The Igbo culture believes that a name can hold someone's entire biography: someone's character, social identity, destiny, present and the future, expectation and attitude of hearers of the name even before they meet the name-bearer. Yet others claim that names are not only for identification but also to connect the name bearer to his or her hopes, calling, and destiny in life. This paper will add to the discussion on some basic facts about naming in Nigerian African culture with an emphasis on Christian biblical concepts.

There is evidence that points to the fact that the correct application of knowledge, with respect to the identity and uniqueness, symbolism, and significance of names is at the heart of why names are important to us as individuals, and society as a whole. In spite of the laudable significance of a name, its spiritual impact is not fully realized even among the Igbos and Christians globally. Names are significantly important and prophetic. In Christendom, great interest has been attached to names, because the meaning of a name can express itself on the character and personality of an individual. This idea is consistent, reasonably, or logically harmonious with biblical scriptures, which is the conceptual framework for this study. All of us are, in the real sense, consumers of names, and we have a need and right to know about the psychological, legal, spiritual, and ethical aspects and meanings of our names. The purpose of this study is to bring to the limelight the significance and importance of covenant naming or names. The Biblical Naming Concept claims that the covenant name given to an individual defines the hopes, calling, and destiny in the life of the individual.

\section{Conceptual Framework}

The Biblical Naming Concept (BNC) was adopted as the conceptual framework for this study. BNC is a divine model based on the King James Bible that claims that human names are covenanted with the name bearer's hopes, calling, and destiny in life. The Biblical Naming Concept is founded on the following five principles among others: (a). A name is rich in Symbolism and can signify one's origin. The word "Genesis" itself means "origin." The Book of Genesis detailing the beginnings of Creation (Genesis 1:1). "Adam," likely derived from the Hebrew word for "ground" Adam was created from the ground's dust (Genesis 2:7), detailing Adam's origin. (b). A name defines the name bearer's mission or purpose in life. The name Simon means "that hears or that obeys" became one of the first people to hear Jesus's call and become Jesus's disciple. Simon, by revelation, correctly identified Jesus as the Son of God (Matthew 16:18). Jesus changed Simon's name to "Peter," meaning "rock" to signify his purpose. The name given to Jesus defines His mission. Before the birth of Jesus, his names were known and declared by the prophet Isaiah as Jesus, signifying one that shall save his people from their sins (Matthew 1:21). Every covenant child of God is known by the name given to him/her by God and 
comes on a mission ordained on the individual by God even before the individual's conception in the mother's womb. (Jeremiah 1:5). This is why names are not just tags for identification.

(c). the name of the individual connects him/her to their mission, message, and ministry. Concerning Jesus, and the names Wonderful, Counsellor, The mighty God, The everlasting Father, The Prince of Peace given to him, all speak of his mission, message, and ministry (Isaiah 9:6). The names of Jesus accordingly, connected Him to His message and ministry. "Nahum" meaning "comfort" preached a message of consolation for God's people because God would handle their enemies (Nahum 1-3). "Micah" meaning "who is like the Lord"; was the gist of his message \& ministry (Micah 1-7). "Joel" meaning "the Lord is God" was his message (Joel 1-3), while "Habbakuk" meaning "to clasp/embrace", was the message and ministry of Habbakuk (Habbakuk 1-3), etc.

(d). the name of the individual also defines his or her characteristics or circumstances. The name "Nabal", meaning "fool", or "senseless" defined the characteristics or circumstances of Nabal. Nabal's wife, pleading on the behalf of her husband for mercy, testifies of this when she told King David to ignore her husband because he behaves foolishly according to his name (I Samuel 25:25). When God told Abram, then 99-years-old, that his 90 years old wife, Sarai will have a son, God had to change Abram to Abraham and Sarai to Sarah to define their new characteristics or circumstances of father and mother of nations respectively (Genesis 17:5). Concerning Sarai, God also told Abraham not to address his wife as Sarai, but Sarah, because of her changed status of becoming the mother of nations (Genesis 17:15-16). Abraham laughed when they taught of the possibility of having a son at the age of a hundred years or Sarah giving birth at the age of ninety years (Genesis 17:17). Because Sarah was caught in the laughter, when she gave birth to a son, he was named Isaac, which means "laughter. Esau and Jacob were born twins. At birth Esau was very hair, hence he was named Esau because of how hairy he was at birth. (Genesis 25:25). Jacob grasping Esau's heel at birth and was named Jacob, which means "that supplants" (Genesis 25:26).

(e). Also, a name initiates the individual to their covenant of blessings. Abram was changed to Abraham (Genesis. 17:56); Jacob changed to Israel (Genesis.17:5-6) in view of the covenant blessings ahead. Evidence from other sources that are consistent with the Biblical Naming Concept has shown that names given to humans are not mere tags or labels but are also symbols of spiritual identity and keys, as it were, to the nature and essence of the name bearer [8] and [9]. Researchers agree with BNC that names given to humans can shape even the faces of individuals [8] and [10] Zwebner, et al., 2017).

Findings from two professors at Harvard University, during a study conducted with thirty-three hundred men who had recently graduated, on whether their names had any pointer to their academic performance, claimed that person's choice of profession, choice of job, residence, spouse, ability to gain employment, academic performance in school, his influence and relationship in a peer group, and business affiliations can be influenced by his name [11]. The name tells a story of who we are, what we shall be and become [12], [11], and [6]. A name has both spiritual and social meaning that can significantly impact the bearer's hopes, calling, and ministry, both positive and negative [10].

\section{Contrasting Researchers of Biblical Naming Concept}

Not all researchers agreed with the Biblical Naming Concept (BNC) that claimed that human names are covenanted with the name bearer's hopes, calling, destiny in life, and the ability to predict behavior. There are contrasting or opposing researches on BNC that claimed that, while a person's name may unconsciously influence his or her thinking, its effects on decision-making are limited [11]. Some other recent research studies have also questioned the link between names and purpose, career choice and success, marriage preferences, and academic achievement. They purport that such a study demonstrates the implicit-egotism effect, arguing that the findings are statistical flukes or accidents that arise from poor methodology [2], [3], and [13]. Shakespeare had the same view that name is simply a tag, evident in his statement "A rose by any other name would smell as sweet", a popular reference to William Shakespeare's play Romeo and Juliet [14]. In contrast to Shakespeare's view, [9] maintained that there is evidence that a Rose by any other name would not smell as sweet after all. Names are regarded not only as labels but also as symbols, spiritual keys, as it were, to the nature and essence of the given being or thing [8]. The contrasting views of these researchers notwithstanding, the Bible (the Word of God), which upholds all things including names (Hebrews 1:3), remains our conceptual framework. This is because the Bible is both theoretically and spiritually justified as true from the beginning (Psalm 119:160), consistent and founded forever (Psalm 119:152), valid, and reliable (1Peter 1:25), eternal (Mathew 5:18), and forever settled in Heaven (Psalm 119:89). This property of BCN makes BCN to be the preferred covenant naming concept or model for this study which focuses on biblical covenant naming in African religion, faith, and culture. 


\section{Literature Review}

Some researchers have focused their understanding of names based on Referentialist theories that majored on two dominant Referentialist views on the semantics of proper names: descriptivism and the direct-reference or causal theory [15] and [16]. The Referentialist view (aside from some specificities related to different versions) a name as a kind of 'disguised' definite description where names simply refer indirectly via their associated definite descriptions. For example, the name Benson would be associated with, say, the definite description refers to the individual from a specific city or country or university. This idea was then refined by a theory called cluster-descriptivism. On the other hand, the causal (or direct-reference) theory frequently thought of as a revival and development of the view on proper names called Millianism, claimed that proper names refer directly to individuals, with no intervening mechanism between names and their referents, adding that names have no meaning, only reference, and do not determine what one can achieve, become, nor do they stop one from reaching their dreams [17].

Other research evidence has claimed that "most popular" baby names might not be the most popular in reality [18]. Continuing, [18] opined that biological, cultural, and social phenomena play a role in baby names in determining if the most populous names given to a baby will result in the baby being popular in life. Because these factors are not known in more detail, a robust analysis of the data would include an uncertainty aspect, thereby rendering such naming trends to remains uncertain. There is a contrasting view that claimed that individuals are by covenant affected positively or negatively by their names because names have meanings [19]. In the Jewish tradition, like the Igbo -Nigeria culture, a child's name was revealed in the same ceremony in which they were circumcised, a sign of the covenant. From the olden days, God's people knew that a good name is esteemed more than silver or gold (Proverbs 22:1).

\subsection{Name and Name Renaming}

There is numerous evidence from scriptures that names have meanings and point to the individuals' hopes and destiny in life, positively or negatively. Names are so important that God has to name or rename some individuals [20]. God named or renamed some individuals so as to establish a new identity or destiny that God wished them to embody. First, God named Himself. When Moses, a servant of God went to enquire from God concerning the way forward for the children of Israel, God disclosed his name to Moses as 'I AM THAT I AM' This was necessary because whatever does not have a name does not seem to exist. Also, Moses needed to know God's name to be able to drive home God's message to the children of Israel. (Exodus 3:14). God named Jesus Christ. The angel announced the conception, birth of a virgin, and the name of the son thereof as Immanuel meaning God with us (Isaiah 7:14). Concerning the Son born of a virgin, it was said that the government shall be upon his shoulder, and his name shall be called Wonderful, Counsellor, The mighty God, The everlasting Father, The Prince of Peace" (Isaiah 9:6). God named John the Baptist through the ministration of an angel who appeared to Zacharias, a minister of God, assuring him that his wife Elisabeth shall bear a son that shall be named John (John 1:13).

The bible also recorded a couple of individuals whose names were changed in other to for them to fulfill destiny. Abram - The word Abram which means exalted father or high father was changed to Abraham meaning father of a multitude. At that time, Abram was about 99years old, wasn't the father of anyone directly, although he was the patriarch and acting father of his clan. God changed his name as a sign of His promise that Abraham would be the father of many nations. (Genesis 17:5). Also, Abram's wife Sarai which means princely was changed to Sarah meaning queen of princes or mother of princes or mother of nations. Despite Sarah's doubts, God intended her to be the mother of many nations as well and instructed Abraham to changed his wife's name from Sarai to Sarah (Genesis 17:15). According to [19]'s claim, it is never too late for a name change in God for a new identity. This claim by [19] is in line with claims by [4], [5], [6], and [7], and consistent with this study's conceptual framework. God, who wanted to make a people out of the descendants of Jacob, sent an angel to change the name of Jacob which means cheater, deceiver, supplanter, to Israel which means God's people. Israel, therefore, refers to a Jew who serves God in a way that allows for Godliness to be revealed for all to see. (Genesis 32:28).

\section{Methodology and Data Collection}

Data collection methods involved extensive collection of data and review of same that are relevant and related to our study. The researchers collected data from peer-reviewed journals, classified and unclassified, King James Bible, and other sources. A narrative research design methodology that enables descriptive, explanatory, synthesis, and analysis of different and related research findings required to draw holistic interpretations or conclusions based on the reviewers' own experience, existing theories, was adopted. The choice of narrative research design was most appropriate where findings resulting from holistic interpretations or conclusions based on the reviewers' own experience, analysis, and synthesis of different and related research data are required [21]. 


\section{Discussion and Findings}

This study is intended to counter-argument to the notion that a name does not predict or define the personality of an individual: the name bearer's mission, message, and ministry, hopes, characteristics or circumstances, calling, and destiny in life, and covenant of blessings. Name matters more than you think in the life and destiny of the name bearer because when the right covenant name is given to an individual, one is good to go for the life 'game' (Isaiah 9:6, John $1: 13$ ). When you change the name, you change the name bearer's 'game' (Genesis 17:5, 17:15). It also intends to point out the fact that though a name predicts or defines the personality of a name bearer, it can only be achieved with the name bearer working and walking in cooperation with the principles of God.

Every name bearer needs God's strength to fulfill his or her calling, and destiny in life. Samson is a typical example of a character in the Bible where the name bearer failed to live to his name. Samson meaning "sun" was an Old Testament hero granted exceptional strength by God, but he did not live to his mane (Judges 15-16). It has been argued that since one does not choose one's own name, such a name cannot reflect one's personality [17]. In all scheme of things, no one chooses his/her parents at birth, yet they are influenced in a way by their parents if they did not change their parents. It is also claimed that the meaning of one's name is relative, and questioned why people with identical names are not having identical personalities. This study counters such claims or arguments. Individuals with the same 'covenant name' with the same meaning are expected to share an identical personality.

A covenant is a conditional promise made to humanity by God usually ratified with an oath. A covenant name is a prophetic name; a name with conditional promise, prophetic by itself, made to humanity by God as revealed, and given to an individual, with the hope and faith that the name bearer will live to the expectations of the hopes, calling, mission, and destiny embedded and propagated in the giving name. If two or more people traveling on the same route to a specified destination will arrive at the same destination. For instance, the name "Nabal", meaning "fool", or "senseless" defined the characteristics or circumstances of Nabal. This was evident in Abigail (Nabal's wife)'s plea for mercy to King David. Abigail requested King David to disregard Nabal emphasizing that folly is with her husband who evidently behaved in line with his name which means fool. ( I Samuel 25:25). If two or more individuals take the name "Nabal" as a covenant name, all will be defined by folly characteristics or circumstances. This is because everything that is named answers to its name or is defined by its name (Genesis 2:19). Covenant name exists for every covenant child of God, and when spoken, announces one and identifies one's hopes, calling, and destiny in life [7] and ( Jeremiah 1:5). You can covenant your name and claim it.

\section{Conclusion}

Based on the analysis, synthesis, and reflections in this study, findings established that names connect one to one's identity, hope, calling, destiny, message \& ministry, character, and personality that is recognized in heaven and on earth by God, angels, and men. The name given to Samuel was recognized in heaven by God and the angels; and when God came calling the young boy within the night, He called out his name as "Samuel" (1Samuel 3:4-10). For researchers and individuals who claim that names are mere tags for identification, I am sure no one will like to take the name Nabal or give the same to their children. However, as we take good covenant names, it is important that we live to reflect what we are called: our identity, hope, calling, destiny, message \& ministry, character, and personality; to make sure that we refrain from conduct that would besmirch our name. The name Saul means "asked for, prayed for" but he did not live to his name. Samson meaning "sun" was an Old Testament hero granted exceptional strength by God, but he did not live to his mane.

There are things to be done to nourish our names: It is not enough to give our children good names, it is sufficient to see and talk good of them. Children are like arrows in the hand of a mighty man which must be guided well to hit the expected target. (Psalms 127:4). Parents are seen as the Archer that bends the bows from which children as living arrows are sent forth. The archer sees (what do you see in your child?) the mark upon the path of the infinite, and bends the bow with might that the arrows may go swift and far. What you see in your child will affect what you say to him/her, the school you send him/her to, the type of clothing you buy for him/her, the kind of spouse you approve for him/her. As the Archer loves the arrow that flies, so the Archer also must love the bow that is stable. Until your bow (your character, integrity, Christian life) is stable, the arrows cannot fly swift and far. We must associate with Jesus and those who have good names (2 Corinthians 6:14-17), live a sanctified life, be faithful to God's house, and never be offended in God. John the Baptist got offended in God and lost his name together with his head (Mathew 11:3-6). Finally, be diligent, reliable, think good of others, and keep your word for "a good name is rather to be chosen than great riches and loving favor than silver or gold" (Proverbs 22:1). All Bible references are from [22]. 


\section{Compliance with ethical standards}

\section{Acknowledgments}

My sincere appreciation and thanks to all the participants that granted me audience during interviews and data collection.

\section{References}

[1] Hess RS. Names of People: Biblical Hebrew. Encyclopaedia of Hebrew Language and Linguistics. 2013.

[2] Gray A. Names in strange places. Linguistics and Philosophy, 2017; 40(1): 429-472

[3] Guercio NL On the Literal Meaning of Proper Names. Análisis Filosófico, 2017; 39(1): 27-49

[4] Flugel I. On the Significance of Names. British Journal of Medical Psychology, 1930; 10(2): 208-213.

[5] Lombard CG. The Sociocultural Significance of Niitsitapi Personal Names: An Ethnographic Analysis. Names, 2021; 59(1): 42-51.

[6] Wieschhoff HA. The Social Significance of Names among the Ibo of Nigeria. American Anthropologist, 1941; 43(2): 212222.

[7] Mensah EO. Name This Child: Religious Identity and Ideology in Tiv Personal Names. Names, 2020; 1-15.

[8] Livni E, Werber C. The name you're given as a child might affect the shape of your face. 2017.

[9] Mabilog P. The power behind names and why God restores our name. 2016.

[10] Zwebner Y, Sellier A, Rosenfeld N, Goldenberg J, Mayo T. We Look Like Our Names: The Manifestation of Name Stereotypes in Facial Appearance. Journal of Personality and Social Psychology. 2017; 112(4): 527-554.

[11] Konnikova M. Why Your Name Matters. Annals of Technology. 2018.

[12] Doja A. Rituals of Naming and Exposure: Meaning and Signification in a Name. Onoma: Journal of the International Council of Onomastic Sciences. 2006; 41(1): .237-270.

[13] Jeshion R. The Significance of Names. Mind and Language, 2009; 24 (4): 370-403

[14] Belsey C. Romeo and Juliet Language and Writing. London: Bloomsbury Publishing. 2014.

[15] Edwards K. Concept Referentialism and the Role of Empty Concepts. Mind \& Language. 2010; 25(1): 89-118.

[16] Recanati F. Direct Reference, Meaning, and Thought. Noûs. 1990; 24(5): 697-722.

[17] Mabuza ME. Individual Names and Personality: A Consideration of some Beliefs. 2011.

[18] Höhle M. Rank uncertainty: Why the "most popular" baby names might not be the most popular. Significance. 2017; 14(3): 30-33.

[19] Zink N, The meaning of proper names Mind;1963; 72(288):481-499

[20] Hartropp J. Why Names Are So Important In The Bible - And So Is Yours. 2016.

[21] Scarnato JM. The value of digital video data for qualitative social work research: A narrative review. Qualitative Social Work. 2017.

[22] King James Bible. (2017). King James Bible Online. https://www.kingjamesbibleonline.org/ 


\section{Author's short biography}

Dr. Felix Chukwuma Aguboshim holds a doctoral degree in Information Technology from
Walden University, Minneapolis MN 55401, USA. He is currently a chief lecturer in the
department of computer science, Federal Polytechnic Oko, Nigeria, where he worked as the
Head of Department of Computer Science, and Director of Campus. A pastor and preacher of
the Word of God through Jesus Christ, equipped with grace and effective interpersonal skills
required to turn around challenging lives and situations. He is also an adjoining lecturer at
the University of America Study Centre in Nigeria.

